\title{
Severe Spinal Infection after Vertebral Fracture Stabilization: A Narrow Escape
}

\author{
Ved Prakash Maurya ${ }^{1}$ \\ D. Elangovan ${ }^{2}$
${ }^{1}$ Department of Neurosurgery, Sanjay Gandhi Post Graduate Institute of Medical Sciences, Uttar Pradesh, India
${ }^{2}$ Department of Neurosurgery, Sri Manakula Vinayagar Medical College and Hospital, Puducherry, India
${ }^{3}$ Department of Plastic Surgery, Sri Manakula Vinayagar Medical College and Hospital, Puducherry, India

V. Mourougayan ${ }^{3}$

M. Ranjini ${ }^{2}$

\begin{abstract}
Address for correspondence Ved Prakash Maurya, MBBS, MS, MCh, Department of Neurosurgery, Sanjay Gandhi Post Graduate Institute of Medical Sciences, Raibareli Road, Lucknow, Uttar Pradesh 226014, India (e-mail: vpmsurgery@gmail.com).
\end{abstract}

\begin{abstract}
Spinal cord injury is typical following fall from height. The thoracolumbar vertebra undergoes maximum fracture following trauma. A 26-year-old man was brought to the emergency department with a history of fall from height. Clinical examination showed weakness in lower limbs with the inability to pass urine. Magnetic resonance imaging (MRI) of spine done elsewhere was suggestive of loss of second lumbar (L2) vertebral body height with compression over the lower end of the cord. Computed tomography (CT) scan of the spine revealed a burst fracture of $L 2$ vertebra with bone fragments protruding into the spinal canal. The patient was taken up for spinal decompression with stabilization. His hospital stay was uneventful, and two weeks after discharge he was readmitted with wound bulge over the operative site. We started him

Keywords

- debridement

- fracture

- wound infection

- trauma

- implants on intravenous antibiotics and did regular debridement of the wound. Later on, he underwent wound closure with flap rotation.

At last follow-up, he was ambulant with bladder and bowel control. During treatment, the titanium implants were left in situ. The decision for implant removal in early wound infection is at the discretion of the operating surgeon, along with the timing and nature of the disease.
\end{abstract}

\section{Introduction}

Spinal cord injury is one of the leading causes of disability in a developing country like India. A recent survey by the world health organization (WHO) suggests fall from height in India and road traffic accidents in Western countries as the leading cause of spinal cord injury. We present the case report of a 26-year-old man who sustained an injury over his back due to fall from a coconut tree. We describe a potential change in the practice of implant removal following early postoperative wound infection to avoid spinal instability and significant risks associated with the second surgery.

\section{Case Report}

A 26-year-old man was brought to the emergency room with a history of fall from a coconut tree. The Glasgow coma scale (GCS) score was full at the time of admission. Detailed neurological examination was done, and he came out to be American Spinal Injury Association (ASIA) impairment scale (AIS) grade B. His preoperative magnetic resonance imaging (MRI) of the spine revealed L2 vertebral body fracture with compression over the lower end of the cord. Computed tomography (CT) scan of spine was suggestive of L2 burst fracture with fragments of bone impinging into the vertebral canal (-Fig. 1).
DOI https://doi.org/

10.1055/s-0040-1713307

ISSN 0973-0508.
(O2020 Neurotrauma Society of India
License terms

()(1) $\Theta \circledast$ 

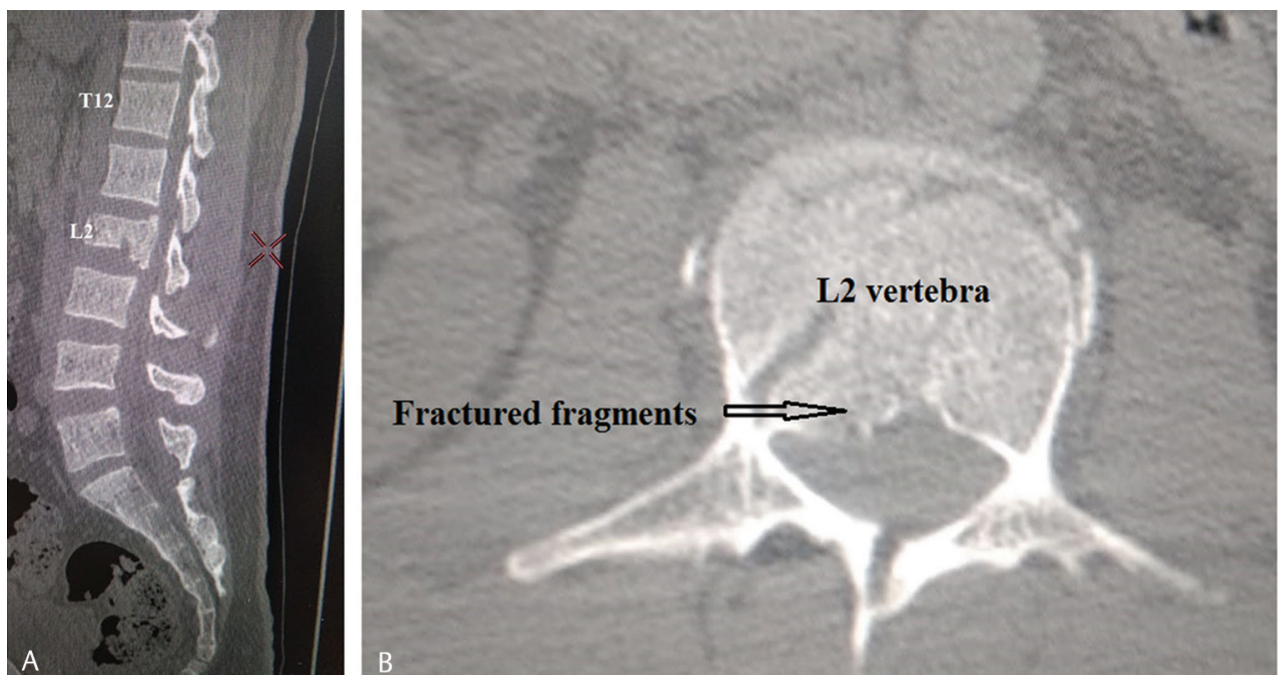

Fig. 1 Computed tomography (CT) spine showing fracture of L2 vertebra causing canal compromise, (A) sagittal and (B) axial cuts.

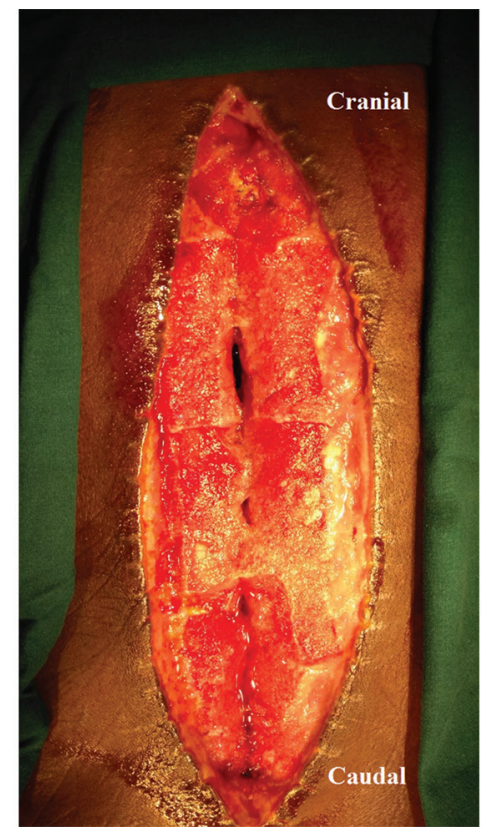

Fig. 2 Wound dehiscence with bright red granulation tissue.

He underwent L1 to L3 laminectomy and pedicle screw stabilization from T12 to L4 vertebrae. At the end of the procedure, the dural tube was pulsating without obvious cerebrospinal fluid leak. He was discharged after 2 weeks with $2 / 5$ power in both the lower limbs, with urinary catheter in situ. After a period of 1 month, he was readmitted with fever and swelling over the operative site. Emergency exploration of the wound was done, and multiple pus pockets involving the deep muscular plane was noted. The implants were left in situ, and vacuum-assisted closure (VAC) dressing was done regularly in the postoperative period. Culture-based antibiotics were started and after a period of 2 weeks, red granulation tissue was noted and the implants were free from gross bacterial colonization ( - Fig. 2). Because

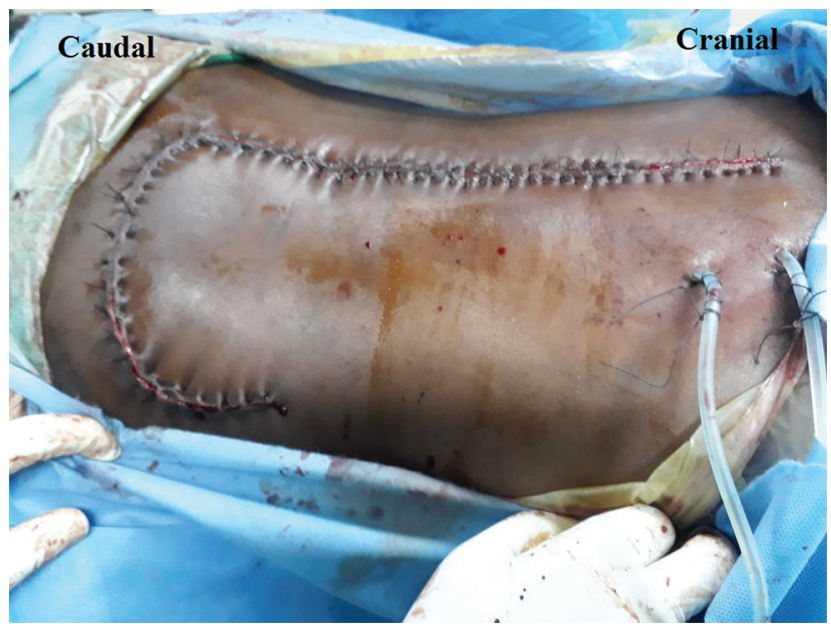

Fig. 3 Operative photo showing wound closure with superiorly based fasciocutaneous transposition flap.

of the significant skin defect, the superiorly based fasciocutaneous transposition flap was raised to cover the implants completely ( - Fig. 3 ). The postoperative period was uneventful with relatively shorter hospital stay and 6 weeks of antibiotics were administered.

In the follow-up visits after 6 weeks, he was ambulant without any support and had bladder sensation. The urinary catheter was removed, and he was observed overnight for retention or incontinence of urine. His motor examination revealed the power of $4+/ 5$ in left lower limb and $5 / 5$ in the right lower limb. There was $20 \%$ sensory deficit in the left lower limb. Postoperative X-ray was suggestive of implants in situ without any significant change in the bone which ruled out deep-seated bony infection ( $\boldsymbol{- \text { Fig. }}$ 4). The operative wound was healthy; 18 months after trauma, he can earn his livelihood by driving an autorickshaw. He still complaints of $10 \%$ sensory loss in the form of numbness over left leg below the level of the hip. 

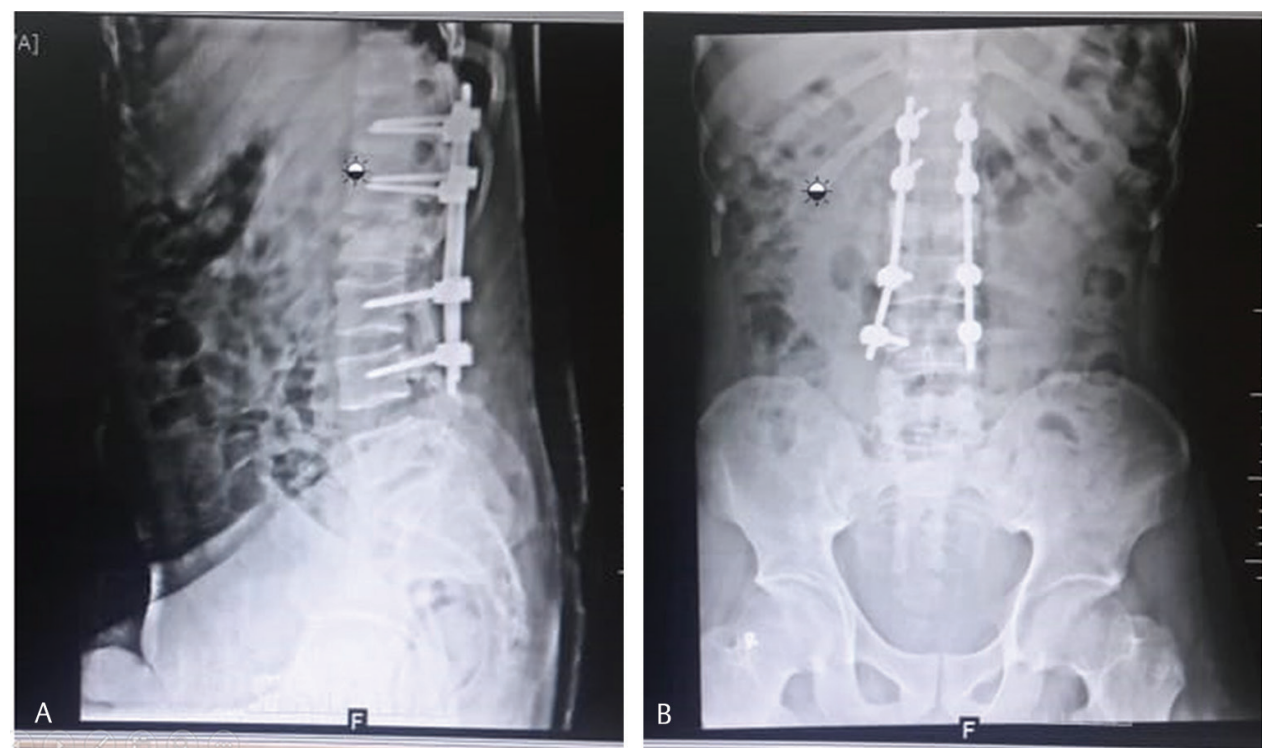

Fig. 4 Follow-up X-ray of lumbosacral spine showing implants in situ, (a) lateral and (b) anteroposterior view.

\section{Discussion}

Fall from a height is a common modality of trauma for cranial as well as the spinal injury. According to a recent WHO survey, fall from height is the leading cause of spinal cord injury in Indian set up as compared with road traffic accidents in the Western countries. Trauma due to falling is associated with fracture of lumbosacral and thoracolumbar vertebrae at the transitional level, which includes T11, T12, L1, and L2 vertebra. These locations of fracture are due to the relative lack of support from the adjacent osseocartilaginous complex.

In our case, this man sustained a fracture of the upper lumbar vertebrae and was not associated with other visceral injuries. The pain was proportionately less as compared with the degree of neurological deficit. The fractured fragment causes compression of the conus along with upper cauda equina fibers. The laminectomy releases the compression, and thoracolumbar pedicle screw contributes to the maximum stabilization of the vertebral column. He developed early deep-seated wound infection, underwent regular debridement, and was treated without implant removal. The bacteriological investigations revealed methicillin-resistant Staphylococcus aureus (MRSA) as the organism responsible for the causing the infection deep to the muscle plane. This main cause of this infection was inadequate preparation of the operative site. The back of the patient was badly soiled with mud and clay, which was left unattended and was for the first time cleaned in the operation room only.

To the best of our knowledge, the infection limited to the skin and subcutaneous tissue are labeled as superficial, and those involving the subfascial and muscle planes are labeled as deep-seated infections. ${ }^{1,2}$ The infection rate is 2.6 to $3.8 \%$ after posterior spinal fusion. The organism mostly responsible for early infection (less than 3 months postsurgery) is Propionibacterium and those responsible for delayed infections (more than 3 months postsurgery) is Staphylococcus aureus. ${ }^{3}$
In our case, there was MRSA as the causative agent, which was treated with intravenous vancomycin, followed by oral antibiotics for 6 weeks each. The pus pockets were located deep to the muscle plane, and the bone and implants were found to be free from bacterial infiltration. There was neither osteomyelitic change over the bone surface nor any evidence of colonization over the implants. The literature available to date suggests implant removal as a necessary step to eradicate the infection completely, else the job maybe half done. ${ }^{4}$ The proper cleaning of the operative site in the ward is something that has to be practiced universally without fail. The duration of contact for the cleaning agent should be a minimum of 5 minutes. To follow WHO surgical safety checklist to deliver the preoperative antibiotics. The implants to be used for stabilization need to be autoclaved twice before fixation, although there is no level 1 evidence regarding double autoclaving of implants before insertion for spinal stabilization. The young age and absence of any comorbidity or substance abuse, along with favorable clinical and hematological picture, supported spinal instrumentation to be left in situ in this case. The VAC decreases the frequency of debridement as well as morbidity associated with wound healing. ${ }^{5}$ The exposed implants were covered with a pedicelled flap, which is a standard of care for significant postoperative spinal surgery defect. ${ }^{6}$ In the Indian scenario, the most common cause of fall from height is workplace accidents, unintentional slips, and suicide attempts. To reduce these accidents, the safety measures need to be implemented with the recruitment of the competent personnel at workplace and construction sectors. ${ }^{7}$ The use of simple bracing technique over the back in executing tasks at altitudes provides significant protection against such injuries.

\section{Conclusion}

The surgical site infection following spine surgery is not uncommon in trauma cases. Timely diagnostics and 
therapeutic intervention would decrease the financial burden and additional morbidity associated with repeat surgical procedures.

\section{Conflict of Interest}

None declared.

\section{References}

1 Bible JE, Biswas D, Devin CJ. Postoperative infections of the spine. Am J Orthop 2011;40(12):E264-E271

2 Chaudhary SB, Vives MJ, Basra SK, Reiter MF. Postoperative spinal wound infections and postprocedural diskitis. J Spinal Cord Med 2007;30(5):441-451
3 Collins I, Wilson-MacDonald J, Chami G, et al. The diagnosis and management of infection following instrumented spinal fusion. Eur Spine J 2008;17(3):445-450

4 Falavigna A, Righesso Neto O, Fonseca GP, Nervo M. Management of deep wound infections in spinal lumbar fusions [in Portuguese]. Arq Neuropsiquiatr 2006;64(4):1001-1004

5 Canavese F, Gupta S, Krajbich JI, Emara KM. Vacuum-assisted closure for deep infection after spinal instrumentation for scoliosis. J Bone Joint Surg Br 2008;90(3):377-381

6 Dietze DD Jr, Fessler RG, Jacob RP. Primary reconstruction for spinal infections. J Neurosurg 1997;86(6):981-989

7 Eren A, Arslan M, Hilal A, Cekin N. Deaths due to fall from a height in Adana. Adli Tıp Bülteni. 2009;14:12-15 